\title{
Flow of Knowledge in Proof-of-Concept Activities: Examining the Problem of Interpretation Using Hermeneutics
}

\author{
Antonio Jose Rodrigues Neto \\ Faculty of Letters, \\ University of Coimbra, Portugal \\ neto@student.uc.pt \\ Maria Manuel Borges \\ Faculty of Letters, \\ University of Coimbra, Portugal \\ $m m b @ f l . u c . p t$ \\ Licinio Roque \\ Department of Informatics Engineering, \\ University of Coimbra, Portugal \\ lir@dei.uc.pt
}

\begin{abstract}
Background. Proof-of-Concept $(\mathrm{PoC})$ is a common practice in several disciplines, and is used in organizations for different purposes, including exploring, producing and disseminating knowledge of new information technology products. Objectives. One intriguing question has motivated the present research: What is the mechanism supporting the flow of knowledge in the context of PoC? Methods. This research was based on direct researcher participation in multiple PoC activities working collaboratively with several PoC practitioners, totaling 30 months of immersion. The research method is ethnography involving observations, notes, semi-structured interviews, and participation in the $\mathrm{PoC}$ world.

Results. After analyzing 459 data points through the lens of hermeneutics, the authors learned that the production and dissemination of knowledge in the context of PoC did not occur only at the end of the PoC activity. Instead, the flow of knowledge occurred in different learning circles (based on hermeneutic circles) as an intrinsic connection to the context. It is the knowledge of the context that allows PoC practitioners to comprehend the construction of the cycles of production and dissemination of knowledge in PoC activities.
\end{abstract}

\section{INTRODUCTION}

Proof-of-Concept $(\mathrm{PoC})$ is a common practice in several disciplines, and can be used by organizations for different purposes including exploring, producing, and disseminating knowledge of new information technology products. A PoC "serves as an instrument of 
knowledge construction in the study and understanding of certain objects (i.e., artifacts and phenomena)" (Neto et al., 2018, p. 270), and has a set of activities for the assessment, understanding, validation, and exploration of those objects.

PoC activities have been studied in several fields, both scientific and corporate (Kendig, 2016). PoC activities are found in innovation/incubation/entrepreneurship centers at universities (McAdam et al., 2009; Sergey et al., 2015); development of project proposals (National Science Foundation, 2014); dissemination of research results for health issues, such as for epilepsy (Schmidt, 2006); research and development of new drugs in medicine (Athilingam et al., 2018; Trieschnigg, 2010); and evaluation of new technology products and patents (Barnes et al., 2009; Chaim et al., 2017; Hirata \& Bernal, 2009; Neto, 2004; Neto \& Da Fonseca, 2007; Silva, 2012; Simitci et al., 2001).

However, we observed that several papers referred to the term Proof-of-Concept, PoC and its variants, as being only a part of their research methodology, that is, as an auxiliary or supporting method. Those studies did not clarify the mechanism for the flow of knowledge during the development and execution of a PoC. Thus, we argue that a lack of understanding of the means by which knowledge flow in PoC activities can compromise and influence organizational memory (Corbett, 2000, p. 289) for the following reasons:

- Absence or distortion of specific details in the tacit and articulated knowledge of organizational members and $\mathrm{PoC}$ practitioners (personal memory).

- Acquisition and collection of information based on myths, prejudices, stories, social rites, normative rules of behavior, documents, artifacts, questions, requirements, etc. Meaning in personal memory depends on how the acquisition and collection of information are contextualized, interpreted, and understood (cultural memory) in the construction and representation of the world.

- Incorporation of technology in the organization, and utilization of technology by people, including PoC practitioners, reflecting on and shaping elements of memory in order to prescribe elements of social behavior in their use, but also leading to a (re)construction of organizational memory (prosthetic memory) based on the knowledge built and disseminated in the PoC activity.

Corbett (2000, p. 292) highlighted the problems of interpretation, which inevitably arise in the process of design and use. Thus, we examine how the formation of the flow of knowledge occurs, which can influence organizational memory and organization members, with possible knock-on or domino effects (Neto et al., 2018). In other words, we reflect on whether the absence of knowledge in the development and execution of PoC by its practitioners can be based on attributions of meanings, that is, from a pre-understanding regarding the unveiling of reality (original world versus the PoC world) that confronts them. Hence, one motivation for our research was to develop a new research perspective of $\mathrm{PoC}$ activities. Another motivation was to contribute to knowledge management in $\mathrm{PoC}$ activities, based on new insights on how the flow of knowledge is formed in PoC activities. Thus, our research question is What is the mechanism supporting the flow of knowledge in the context of PoC?

\section{RESEARCH METHOD}

We adopted a qualitative approach within the scope of Information Systems, specifically in the domain of Information System Development. We also contextualize this research in Information Science that seeks to "establish a homogeneous scientific approach to study the 
various phenomena that surround the notion of information ... [The task of Information Science] is the study of the properties of the communication processes that must be translated into the design of an information system" (Saracevic, 1996, p. 46).

Our qualitative research was carried out in the natural PoC habitat, where there is a direct source of data and the researcher becomes an instrument of research, and where the environment and its practitioners were holistically observed and analyzed, while not being reduced to variables, but rather they were observed as a whole. We present our research method as an interpretive and qualitative paradigm of an inductive and descriptive logic, characterized as exploratory and ethnographic research (Angrosino, 2007; Coutinho, 2015; Gil, 1989; Lazar et al., 2017).

According to Coutinho (2015), in the inductive construction of a new theory, the central role assumed by the researcher necessarily leads to the production of another type of knowledge, which in the context of our study is a clarification of the geography/mapping of the flow of knowledge in the context of PoC.

Our investigation begins with a set of observations and participation in the natural PoC habitat, following Glaser \& Strauss (1999, p. 37) who advised that the "effective strategy is, at first, literally to ignore the literature of theory and fact on the area under study, in order to assure that the emergence of categories will not be contaminated by concepts more suited to different areas. Similarities and convergences with the literature can be established after the analytic core of categories has emerged."

During our methodological path, we realized that when we started our observations, we actually started reflections in an intuitive and unconscious way related to the data and phenomena collected and observed during the development and execution of the PoC. In other words, throughout our journey, when faced with these phenomena, we always questioned Is this a flow of knowledge? and if so, How is it formed? However, many times in our investigation we realized the need to extend our horizon and seek different perspectives in other theories in the scientific literature, in order to compare and contrast the data collected, observed phenomena, as well as our own questions, as a result of our reflections in relation to our research question.

Regarding our immersions in the natural PoC habitat, we have adopted a combination of observation (i.e., acquiring narratives), notes, semi-structured interviews, and participation in the PoC world, which we call PoC scenarios. Thus, we highlight this combination by characterizing it as ethnographic research (Angrosino, 2007; Lazar et al., 2017) which according to Lazar et al. (2017, p. 230) is based on "deep immersion and participation in a specific research context to develop an understanding that would not be achievable with other, more limited research approaches."

In this research, our goal with semi-structured interviews is to encourage PoC practitioners "to speak." The more they talk about $\mathrm{PoC}$, the better they will situate themselves in the context of the PoC activity, and the better we can understand how these practitioners act in the development and execution of the $\mathrm{PoC}$, with respect to the production and dissemination of knowledge. This can help to clarify the relation between the context of the PoC outcome and the engineering context of the PoC.

Therefore, the questions emerging from our conversations with these practitioners were not limited to a specific set of ready-made questions, such as What is a PoC? or How do you document the final results in a PoC? New questions naturally emerged in the course of our interactions with the PoC practitioners. These interviews were not "focused on specific questions of functionality and design. The goal is to understand the needs and challenges presented by a particular situation [e.g., the flow of knowledge in the context of PoC]. Once 
those needs are well understood, you can move on to specific details that would lead to a concrete design" (Lazar et al., 2017, p. 190).

We developed this study based on data collection resulting from our immersion in the natural $\mathrm{PoC}$ habitat, that is, we totally immersed ourselves in the $\mathrm{PoC}$ world and analyzed how five different Information Technology (IT) companies developed and executed PoC activities with respect to several organizations (i.e., potential clients). In that, we aimed to observe, document, and interact with several PoC practitioners and their way-of-doing-things (ethnographic exercise) in the PoC context, thus eliciting knowledge of practices in their natural habitat(s).

In other words, we adopted a research method based on an ethnographic exercise which reflects "the notion that true understanding of complex human practices and contexts requires in depth, engaged study" (Lazar, Feng, \& Hochheiser, 2017, p. 231), where individuals (i.e., PoC practitioners) may describe what they do in a way that is inaccurate due to a lack of understanding of what needs to be communicated to accomplish a PoC outcome (Neto et al., 2020a, p. 130).

Thus, our research was based on our direct participation (Angrosino, 2007; Lazar et al., 2017) in multiple PoC activities, 80 in total -50 as non-interventionists and 30 as interventionists (practitioners) working collaboratively with several PoC practitioners; 97 in total. In this process, model concepts were used to communicate with other practitioners, while referring explicitly to the practices and activities involved. Later, the data collected were analyzed based on our observations of two groups of practitioners, namely (i) PoC specialists - those who execute PoC for high-performance information technology (IT) data infra-structure organizations; and (ii) PoC participants - non-specialist actors interacting along with the PoC specialists in diverse roles (e.g., customers, solutions architects, IT consultants, database administrators, among others). As both observers and practitioners, our interest was in tracing how these concepts could help make explicit reflections.

Our method was based on interactive observations and constructions on how the knowledge flow evolves and relates in the PoC activity system (Neto et al., 2020b), especially with respect to its formation (construction) in the context of PoC.

\section{Introducing Philosophical Hermeneutics}

For the data analysis, we adopted the perspective of philosophical hermeneutics that originated with the German philosopher Martin Heidegger (1889-1976) and further developed by Hans-Georg Gadamer (1900-2002). Heidegger (2005) stated that understanding, which precedes interpretation, is intuitive and (pre-)reflective, that is, the idea of truth points to an agreement or pact between the judgments of the interpreters, a fact that we can observe between the PoC practitioners and their world. Heidegger also left us a fundamental lesson by pointing out that words do not have a fixed or unique meaning, unrelated to any context (Batista, 2012). According to Schmidt (2012), hermeneutics is the reverse process of discovering the thoughts behind an expression.

Gadamer (2013) argued that there is an interdependence between the part and the whole, known as the hermeneutic circle, where "complete knowledge is always in this apparent circle" and "where each particular [part] can only be understood through the general [whole] of which it is a part, and vice versa" (Schmidt, 2012, p. 23). The same author considered hermeneutics as something inseparable from our existence, that is, we are interpreting at all times, whether the focus is on objects, situations, other people, or even ourselves. In the present study, we propose that the same applies to the context of PoC in 
relation to the actions (movements) of its practitioners during the development and execution of PoC. For Gadamer, interpretation takes place in different circles based on the hermeneutic circle, the truth being nothing more than the composition of these circles, that is, something consensual, agreed upon intersubjectively among the participants of that circle.

We highlight the definition above concerning the interpretation/comprehension and the construction (formation) of different circles in the PoC context. We perceive an inseparable relationship of these interactions and dialogues of its practitioners and the context in the search for knowledge during the development and execution of PoC.

Further, we consider that understanding is a process based on dialogue between the past and the present (Gadamer, 2008), which occurs when a PoC practitioner presents his/her assumptions to another, such as a client involved in the $\mathrm{PoC}$, knowing that some of the assumptions or certainties related to $\mathrm{PoC}$ outcomes could be affected during that meeting. In other words, such assumptions and certainties are susceptible to future reviews in order to contribute to the improvement of the activity itself and its practices.

Understanding, therefore, appears as something produced in the dialogues instead of something reproduced merely by an interpretation, when faced with a text, action, situation, or result. This is the meaning that was worked on by Gadamer, under the inspiration of German philosopher Georg Wilhelm Friedrich Hegel, for whom the experience is interpreted as being the product of the encounter between consciousness and an object (Batista, 2012; Neto et al., 2020a).

Stagliano (2016) cited by Neto et al. (2020a, p. 129) points to hermeneutics, which can be understood as a "set of theories to provide the interpretation of something, not only of written texts, but of everything that may give some meaning." Thus, hermeneutics is always related to a situation or to a context (Portocarrero, 2010).

\section{RESULTS AND DISCUSSION}

During our immersion in the natural habitat of $\mathrm{PoC}$, we encountered an issue highlighted by Paul de Bruyne et al. (1991), that the idea of scientificity encompasses both unity and diversity in the sense that one should be able to find deep similarities in all actions inspired by the same idea or conceptual knowledge. This perspective informed our analysis of the construction and dissemination of knowledge in the context of PoC, including the interpretations and understandings of PoC practitioners of the evaluation results regarding the performance of technological artifacts (e.g., software). Scientificity should not be restricted to a certain form of knowledge, because PoC can involve different ways of doing things, and different forms of interpretation and understanding.

Over a period of approximately 30 months of immersion in the natural $\mathrm{PoC}$ habitat, we collected and analyzed 459 data points - 391 PoC scenarios (e.g., PoC dialogues), 11 semistructured interviews with several PoC practitioners, 5 theoretical sketches, and 52 practical sketches observed and collected in the context of PoC. Later, we analyzed all the gathered data with the aim to identify and clarify the flow of knowledge in the context of PoC. We adopted the PoC practices context model proposed by Neto et al. (2020b) to map the PoC scenarios (e.g., dialogues) against the $\mathrm{PoC}$ practices with the aim to simulate a large knowledge network where each data collection event, which we term nodes, "connects" to its respective PoC practices.

We sought the knowledge flow in a PoC context grounded by several interaction cycles in the development and execution with different and complex PoC activities which overall translates to the development of a type of knowledge network in the context of PoC. In other 
words, with the birth of a PoC, several other mini-activities can arise within the PoC itself or in other PoC activities, depending on multiple factors, for example, the lack of understanding of the performance of the technological artifacts under study, the results obtained during the $\mathrm{PoC}$, as well as the need for a greater understanding and interpretation of the phenomena emerging from the development and execution of a PoC activity.

We envisage the knowledge flow during the activities of the PoC, which is characterized with a characteristic composition and similarity to information systems which have "a socio-technical composition with hardware, software, people and processes integrated into a complex, purposeful whole" (Hasan, 2003, p. 4).

According to the same author, the development of socio-technical systems (i.e., the PoC activity) involve "activities of design and construction [that] are akin to grounded approaches to research such as pragmatism, the philosophy that truth is what works in practice. In IS [Information Systems] activities of interest are found in the development of socio-technical systems involving computer-based tools. Typical methods used in IS research, where the design and construction of a system is involved, are observation, action or participant research often with various forms of prototyping (Baskerville \& Wood-Harper 1998). The evidence for validity of this type of research, in terms of knowledge creation, is usually referred to as proof of concept." (Hasan, 2003, p. 7)

On the other hand, we envisage that the PoC activity, while being a source of innovation for organizations and their practitioners in the search for knowledge of their objects and phenomena under study, also presents itself as a potential source of problems, requiring translation and negotiation actions (Engeström, 2001). Thus, we conclude that the process of appropriation of knowledge in the socio-technical phenomenon of PoC occurs in a non-linear way through activities mediated in the relationships between these practitioners and in the development and execution of their practices, therefore, being closely associated with a context while not being characterized as solely a sequence of steps to be followed by their practitioners.

In other words, the appropriation of knowledge occurs inside a hermeneutic circle (Gadamer, 2008; Nixon, 2017; Schmidt, 2012). However, during our immersion in the natural PoC habitat, we identified a "dilemma" that is implicit in the PoC activity, involving the development and execution of the $\mathrm{PoC}$, its practitioners, the organizations involved and the technological artifacts under study, when contrasted with the results of other PoCs.

We also see that the same dilemma applies to (i) the interpretations of the phenomena and results of the performance of technological artifacts and their phenomena under study by their practitioners; (ii) the interpretation and understanding of the requirements to be explored during the PoC; (iii) prejudices and assumptions, often "brought" unconsciously by its practitioners in the development and execution of this activity; among many others. Yet again, this dilemma also applies to situations in which practitioners and organizations have diverse beliefs of how to act and see things in the context of $\mathrm{PoC}$, thus contributing to the increase in development and execution problems (and also understanding) of this activity, in addition to influencing their own reflections and understandings regarding the performance of the technological artifacts under study.

According to Nixon (2017), interpretation is not a complement to understanding but rather an "explicit form of understanding," where "understanding is always interpretation" (Gadamer, 2013, p. 318). Therefore, after our immersion in the natural PoC habitat and our data analysis, we identified the flow of knowledge in the context of $\mathrm{PoC}$ as being connected in a hermeneutic way, since all cases of understanding necessarily involve interpretation and application (Gadamer, 2013), whereby the philosophical hermeneutics proposed by Gadamer 
sought to identify a behavior in order to express a perceived world, whose understanding interpreted and explained its behavior (Deetz, 1973).

In our investigation, we envisage this behavior in order to express this world perceived in the movements of $\mathrm{PoC}$ practitioners, where the understanding of this world is based on the interpretation, compression, and application of those practices in the context of PoC. That is, in a relationship of two socio-technical worlds (contexts), the original world versus the world of PoC, with the aim to clarify the knowledge flow and interpretations in PoC.

\section{The Production of Meaning and the Potential Domino Effect in the Context of PoC}

We highlight the dialogues (PoC scenarios) that the actors in the context of the PoC engage in as being the drivers (i.e., impetus) of the PoC activity. These conversations transform the engineering and design of the $\mathrm{PoC}$ into movements that connect to one or more practices. We learned that many practitioners in the context of $\mathrm{PoC}$ have a constructivist position during the development and execution of $\mathrm{PoC}$, which is "an approach to learning that holds that people actively construct or make their own knowledge and that reality is determined by the experiences of the learner" (Elliott et al., 2000, p. 256).

However, we note in several situations that there is an absence of inductive thinking associated with the engineering of a context, which we understand and seek to represent through an allusion to the Black Swan Theory, where we highlight thoughts of Nassim Taleb in The Black Swan: the impact of the highly improbable, where the problem with specialists is that "they do not know what they do not know" (Taleb, 2010, p. 147).

According to the same author, the lack of knowledge and an illusion about the quality of his own knowledge come together, in that the same process which makes him know less also makes him satisfied with his knowledge, contributing and potentiating an "inability to predict outliers implies the inability to predict the course of history" (Taleb, 2010, p. xxiv). In other words, in our research we highlight the importance of constructivist thinking during the development and execution of $\mathrm{PoC}$, but we also emphasize the conversations supported in the context of this activity as essential for the production of meaning and opportunities for innovation, especially in relation to practice-based knowledge as a whole in the context of PoC (Figure 1).

As can be seen in Figure 1, we present a scenario composed of two practitioners working in the context of the $\mathrm{PoC}$, where we see that one production of meaning (step 2 in Figure 1) supported by prior knowledge or the results of other PoCs without knowledge of the context (step 1 in Figure 1) can provoke a "snowball" phenomenon which may subsequently cause what we term the domino effect (step N in Figure 1) in the context of PoC (Neto et al., 2018, p. 273), thus impacting the production and dissemination of knowledge for the current or new PoC activities.

The domino effect in the context of PoC can contribute to increasing the probability of producing and disseminating "deficient" knowledge that is called illusory knowledge in the context of $\mathrm{PoC}$, which can potentially be propagated throughout the whole $\mathrm{PoC}$ knowledge network. In other words, we envisage that this given knowledge (that is, what someone imagines to be knowledge in the context of the $\mathrm{PoC}$ ) without a context, becomes just a tangle of information (or an illusion of a proper sense) in the context of PoC with, for example, the excerpts from our ethnographic exercise in bold type in Table 1. 

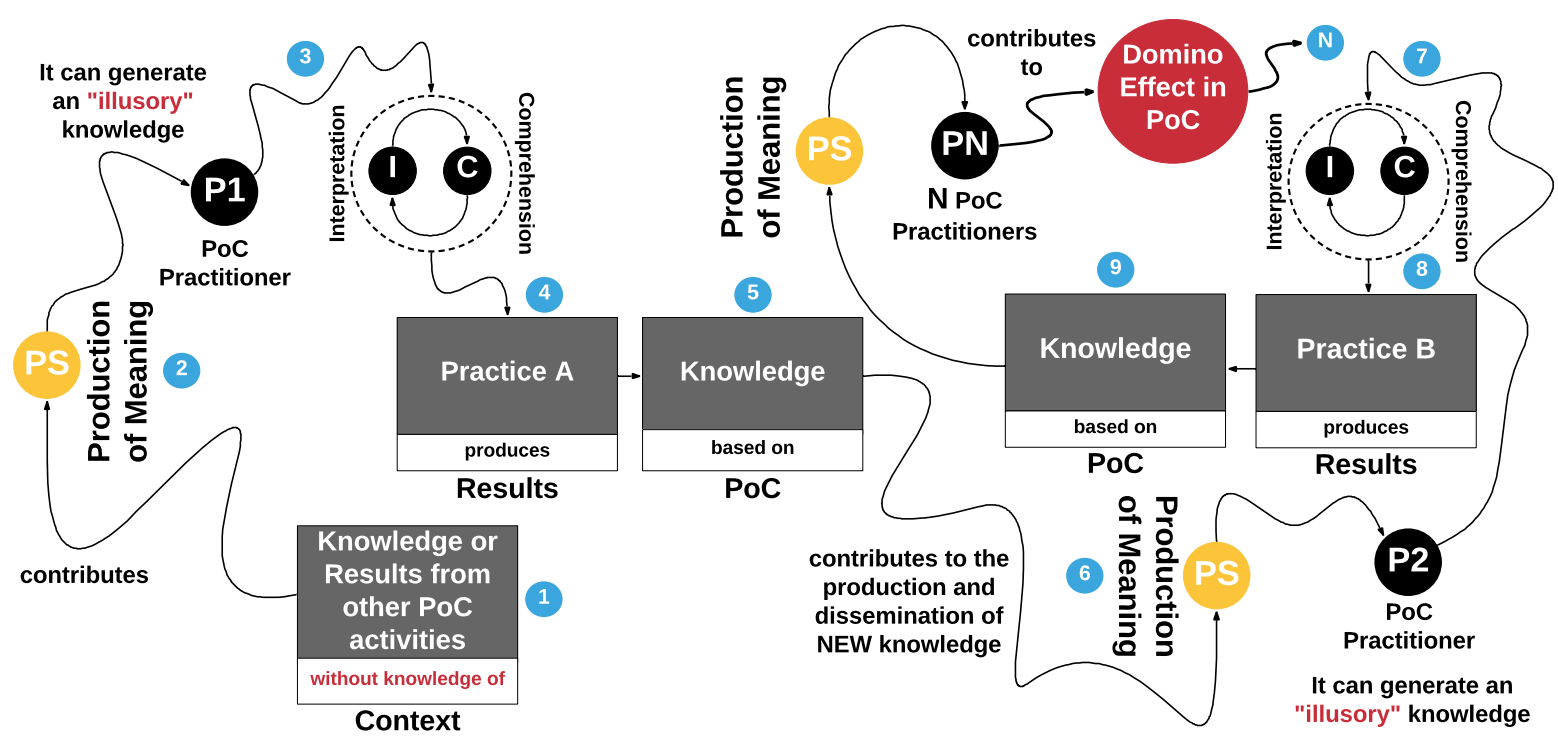

Figure 1. The illusory production of meaning and the domino effect in the context of PoC

Table 1. Excerpts from our ethnographic exercise: the illusory knowledge in the context of PoC

This is internal for us, so no one is holding us to the fire. I merely need to use the max IOPS as a gauge. Check out columns $O$ and $P$ for this spreadsheet. I am proposing a solution to reduce a data center footprint for this customer. However, I need the IOPs for both platforms (Lady-v10 and The Tramp-V11) [anonymized names] to figure out the potential \$/IOP. Don't need to run any specific application to generate IO or synthetic workload tool or anything. Instead, what is the fastest you've ever seen each platform run? Lady-v10 [anonymized name] topped out at E1550 K IOPS? Have you maybe pushed 1650 K IOPS under the right conditions? Has the Tramp-V11[anonymized name] exceeded two million IOPS ever?

Your customer needs to consider a more realistic workload for his application. Doing $100 \%$ reads - $512 \mathrm{~KB}$ random IO just because the competitor $X$ wants to influence [sarcasm] advise everyone on the planet that is the right block size to be used everywhere. Come on ... and if your application does not use that block size?

Can you do one last test with IO-Mini [anonymized name] configured to maximum IOPS? The customer wants to see the latency when the configuration is not at the limit, like $200 \mathrm{~K}$ IOPS. He wants to see if the latency is the same as when the machine is at the limit or if the latency is less than the max test. According to the customer, one of the competitors presented performance numbers with a flat latency (no variation) whatever the number of IOPS is (???) ... It looks like some of our competitors are using caching effects somewhere in the data chain ... Can you do this last test?

In this way, we understand that the capture of reality is performed when the practitioner in the context of PoC earnestly seeks to perceive the world in which he/she lives, not only based on his/her sui generis perspective, but also in relation to the different perspectives and actions of other actors in the context of this activity. Note that this set of different 
perspectives in the context of $\mathrm{PoC}$ provokes new thoughts and reflections in order to contribute to the formation and improvement of hermeneutics circles (Neto et al., 2020a).

In other words, the production of meaning and the flow of knowledge in the context of $\mathrm{PoC}$ are grounded by the hermeneutic circle and are based on the movements of interpretation and comprehension using the "knowledge network", composed of:

- Movements: Practitioner-performed actions or codes for construction and dissemination of knowledge during PoC development/execution (e.g., conversations in the sociotechnical context) (Neto et al., 2019).

- Competencies: Condensed practitioner skill set built from a toolbox of identified movements (actions or codes) (Neto et al., 2019).

- Scenarios: Raw dataset containing information such as dialogue and sketches which occurred during PoC activities.

- Practices: In the context of our research, we adopted the term practice (Neto et al., 2018, p. 271) based on Schön, who offered an "approach to the epistemology of practice based on what some practitioners actually do" (Schön, 1983, p. viii).

Therefore, during these movements of interpretation and understanding, practitioners and their activities create and promote knowledge, where the flow of knowledge contributes to their own evolution, in addition to the production of new activities (Figure 2).

As can be seen in Figure 2, any understanding in the context of PoC is born with prejudices, where practitioners adopt, modify or reject these prejudices as the development of this activity proceeds. In other words, PoC Development and PoC Execution proceed in a "hermeneutic circle" (see the circles of interpretation and comprehension in Figure 2) where the flow of knowledge is characterized by back-and-forth movements between these prejudices that would lead to practices in the context of $\mathrm{PoC}$ and the knowledge that we

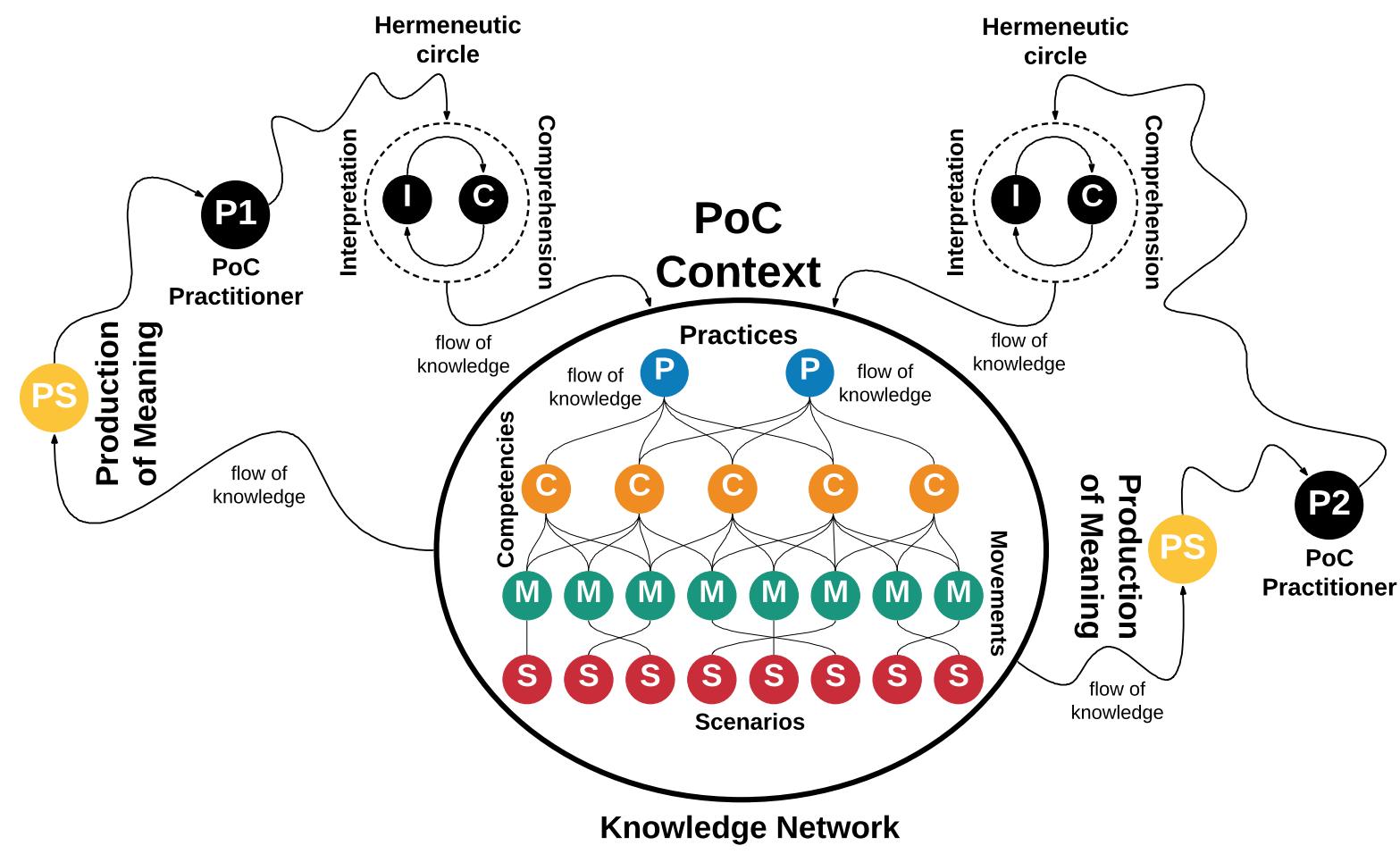

Figure 2. The production of meaning and the flow of knowledge in the context of PoC 
derive from those movements. In other words, knowledge is not only that material which is produced and presented at the end of the PoC activity, for example, equipment $\mathrm{X}$ was able to perform Y Input/Output Operations Per Second (IOPS) with a response time of Z milliseconds. In that, the production of meaning and the flow of knowledge are formed with a grounding on a practice context model (Neto et al., 2020b) with connections to the practitioners' hermeneutic circles.

On the other hand, if there were no prejudices to modify, understanding would be impossible and unnecessary. However, the practitioner in the PoC context is not an isolated entity in the knowledge network, where that practitioner and the knowledge both live in a given context and both interact with this context, while simultaneously influencing and being influenced by the context.

Therefore, hermeneutics presents "itself in the present time, in the culture of a particular group, to seek the meaning that comes from the past or even the present, from a worldview of its own, involving in a single movement the being who understands and what is understood, which is specifically what happens in [the world of] PoC" (Neto et al., 2020a, p. 130). Thus, reflecting on what happens in the world of PoC supported by hermeneutics can reveal problems and also help to clarify and understand the dimension(s) of the production of meaning or the phenomena inherent in the context model of PoC practices.

In the next sections, we present six different scenarios resulting from our immersion in order to highlight the hermeneutic nature and the flow of knowledge in the context of PoC. Due to page length constraints, we are unable to present and describe the 459 datasets from our ethnographic exercise.

\section{The "Dilemma" of the Final Results in the Context of PoC}

Inspired by Gadamer (1976), who affirms that all understanding is interpretive because it happens within the hermeneutic circle, within which the interpreter moves from a meaning projected from the whole to the parts, and then back to the whole, we conclude that the management of knowledge in the context of PoC needs to be based on the combination of a conceptual-relational model of the context of practices and hermeneutical principles, where the isolated application of a practice or an unaccompanied interpretation of a context can contribute to increasing the probability of the domino effect in PoC, as in Table 2.

The excerpt in Table 2 indicates the final results of two experiments (i.e., the set of tests to be developed and executed in PoC) in the PoC activity. We emphasize that in the lack

Table 2. The dilemma of the final results in the context of PoC

\footnotetext{
Here are the final results. We will send the final documentation in a couple of days. Could you please double check if they have any default template to document all the results or if they are OK without any predefined format? I plan to send all log files from the workload tool combined with the performance stats we collected on the storage layer. I would like to take this opportunity and thanks all involved in this PoC for this great accomplishment: (1) $4 \mathrm{~K}$ Random Read-expected results: $1 \mathrm{M} \mathrm{IOPS}$ and $0.4 \mathrm{~ms}$ latency - actual results: $\sim 2 \mathrm{M}$ IOPS and 0.24 ms latency; and (2) 80\% Random (70\% reads/30\% writes)@19 KB and 20\% Sequential (50\% reads/50\% writes)@2 M-expected results: 340 K IOPS and 0.5 ms latency-actual results: $750 \mathrm{~K}$ IOPS and $0.35 \mathrm{~ms}$.
} 
of general understanding and the understanding of the context, the practitioners could establish some interpretations (or rather misinterpretations) as in the following assessments:

- The documentation indicates that the technological artifact had a performance of $2 \mathrm{M}$ IOPS in a response time of $0.24 \mathrm{~ms}$. However, we cannot assume this to be an "absolute truth" (i.e., an absolute piece of knowledge that can be applied in full in any context). We do not question the fact that this technological artifact is capable of achieving this performance, but what was the construction of the context (i.e., the formation of its knowledge network) that contributed to the production of this truth? In other words, we understand the production of meaning in the context of $\mathrm{PoC}$ as a product of the interpretation and understanding of its practitioners in association with a context.

- Thus, we do not understand in terms of a description of a context, a "tangle" of results (i.e., a mixed batch of results) as a result of the set of practices in the context of the PoC. We understand that these results were developed from the interpretation and understanding of a practitioner in a particular world (e.g., a particular context of PoC). In other words, we can view the PoC context as a complex network of knowledge which, despite this activity having some similarities in relation to other PoCs, its formation (that is, its nodes, its connections, and its percolation states) differ from one $\mathrm{PoC}$ to another.

- We observed in several situations that practitioners think that the final results are characterized as the final phase of $\mathrm{PoC}$ activity, that is, the "absolute truth" in $\mathrm{PoC}$. We noticed several practitioners using these results to contribute to the production of meaning in other PoCs, but without a proper interpretation and understanding of the context. For example, if we reflect on this scenario without contextualizing it, can we assume it to be an "absolute truth" that the technological artifact will be able to present the same performance using any system application or software tool for the IO generation and simulation?

- Likewise and supported by hermeneutical principles, we question: (i) Could the technological artifact be able to achieve this performance exclusively due to the use of the IO generation and simulation software tool (the answer to which we do not know) used in this experiment? or (ii) Could the technological artifact only be able to achieve this performance due to the use of the IO generation and simulation software tool (the answer to which we do not know) used in this experiment?, among others.

In the context of $\mathrm{PoC}$, we highlight the relevance and the need for interaction between all actors in the context of PoC and its multiple interpretations. Based on Gadamer's (1999, 2013) philosophical hermeneutics and the set of hermeneutic principles proposed by Klein and Myers (1999), we understand that the flow of knowledge in the context of PoC cannot be seen from the understanding of a single interpreter (e.g., the production of the documentation in the excerpt presented in Table 2), where its meaning must in some way always be negotiated in order to contribute so that the production of meaning of this activity can reach a degree of harmony, that is, a consensus in the production and documentation of these PoC results.

In other words, we conclude that knowledge management, for example, the identification of the flow of knowledge in the context of $\mathrm{PoC}$ is a fusion of several horizons of its practitioners, where something that was produced during the development and execution of a $\mathrm{PoC}$ is not necessarily reproduced (interpreted) in the same way by an interpreter, such as another practitioner in the context of $\mathrm{PoC}$ or a different practitioner in another world of $\mathrm{PoC}$. 
Thus, we highlight this interaction to point out that these practitioners can change their horizons from the appropriation of concepts and prejudices of other actors with whom they are interacting, as well as transform their actions from these changed horizons.

Therefore, we highlight Gadamer's observation in relation to the production and dissemination of knowledge in the context of PoC that the "harmony of all details with the whole is the criterion of correct understanding. This process of understanding is the interaction between the movement of tradition and the movement of the interpreter" (Gadamer, 1999, p. 293).

\section{Performing Resilience Tests in PoC Activities}

The excerpt in Table 3 is from a dialogue between some actors in the context of the PoC during the performance of several resilience tests in a data storage system solution (Almeida, 2006; Neto, 2004). In a specific resilience test, the "expert" practitioner actor on the client side (i.e., on the organization side - a potential new client) considered the results obtained from this particular experiment to be unsatisfactory.

The resilience test was based on removing (i.e., pulling) a data disk from a data storage system shelf, that is, the Boo-Boo solution (anonymized name) in version 0.9 of their operating system, where the detection time of the removal of this disk was approximately 97 seconds. However, based on hermeneutics, we highlight the thought of Zimmermann (2015, p. 51) in this specific scenario: "If mediation as the central movement of understanding is the heart of hermeneutic experience, then application is its motivating power, its soul."

We understand that this experiment was initially built based on a certain knowledge of a practitioner in the PoC world, where the act of manually pulling a disk out of a shelf in a data storage solution can be understood, from the perspective of hermeneutics, as the application in the hermeneutic circle. However, although we agree that electronic components of technological artifacts could fail, we question whether this application can be "translated" into an original world, where we do not envisage "disks simply flying out of shelves." In other words, data disks in a data storage system do not fail and "physically exit the slot they are in", they simply fail in situ.

Therefore, if the practitioner's intention was to simulate a failure in order to simulate what could happen in the original world, this application could have been achieved by executing specific commands in the data storage operating system in order to induce the failure of this element. When simulating this failure by manually pulling a disk from the shelf, we understand that the production of meaning is compromised when there is no knowledge of the intention of this practitioner. This information may be passed on to other actors in the PoC, who may conclude that "the Boo-Boo (anonymized name) takes 97 seconds to detect a

Table 3. Performing resilience tests (experiments) in PoC activities

During the resilience tests, when manually pulling a storage disk out of the shelf, the BooBoo equipment [anonymized name] in version 0.9 took approximately 97 seconds to detect the removal of the disk and mark its failure. Despite meeting our proposed requirement for resilience and failure detection, we consider this result to be unsatisfactory, as this detection and failure should be immediate. 
failure". However, did the PoC practitioner pull the disk out of the shelf only because it was the only way he knew to simulate a failure?

We learn from hermeneutics that there is no right or wrong in PoC activities, but there is a system of what does and what does not apply to the intention and context of PoC activity. In the context of PoC, we highlight the need to understand the other practitioners' thoughts and how those thoughts were influenced by the culture and the context they experienced, meaning, their experience in a past context which is not applicable to the current context. We highlight the relevance of hermeneutics in the context of PoC in order not to disguise the distance of understanding between practitioners in the context of $\mathrm{PoC}$ (that is, in the role of actors and interpreters), where the "notion of belonging, which immediately raises the problem of the subject - object relation and prepares the way for the subsequent introduction of the concept of distanciation" (Ricoeur, 2016, p. 175).

Therefore, the role of hermeneutics in the context of PoC is to contribute to an explanation of this understanding among its actors in order to reveal the meanings in the different contexts, indicating how the current situation emerged and how it developed throughout the PoC activity, where for each class of manifestations there is an elementary form of understanding. Such understanding first begins in practical or pragmatic situations in common interactions which presuppose that, through external empirical expressions, we can familiarize ourselves with aspects of other people's internal lives that those others have expressed (Schmidt, 2012).

\section{The Use of the Average in Performance Experiments in the Context of PoC}

The next scenario (see excerpt in Table 4) presents a discussion among practitioners in the context of PoC, which is assumed to be during the practice of Negotiating (Neto et al., 2020b, 2019), regarding the use of the average, during experiments in the context of PoC. The discussion was guided on how to perform $\mathrm{I} / \mathrm{O}$ operations in order to obtain an average data block size of $41 \mathrm{~KB}$, being a distribution in the use of data blocks of $8 \mathrm{~KB}, 32 \mathrm{~KB}, 128 \mathrm{~KB}$ and $256 \mathrm{~KB}$ in read and write operations.

We highlight Gadamer's thinking that understanding must always occur within a hermeneutic circle, from which we cannot escape objectivism, for example, the adoption of a simple mathematical calculation in order to find an average of I/O (Input/Output) operations in an experiment in PoC. According to Gadamer, the hermeneutical dialogue between the question and answer can lead to an event of truth where the interlocutors are able to reach agreement on the evident character of the truth that they have experienced.

Table 4. The use of the average in performance experiments in the context of PoC

An average of $41 \mathrm{~KB}$ of block size is not even a multiple of two. Another thing is what are they expecting from this $41 \mathrm{~KB}$ average? If the set of blocks they want to observe is composed of $8 \mathrm{~KB}, 32 \mathrm{~KB}, 128 \mathrm{~KB}$ and $256 \mathrm{~KB}$, an approximate average of $41 \mathrm{~KB}(41,984$ bytes) can be obtained from different combinations, for example: $(2 \% 8 \mathrm{~KB}, 6 \% 32 \mathrm{~KB}$, $60 \% 128 \mathrm{~KB}$ and $32 \% 256 \mathrm{~KB})$ or $(18 \% 8 \mathrm{~KB}, 10 \% 32 \mathrm{~KB}, 22 \% 128 \mathrm{~KB}$ and $50 \% 256 \mathrm{~KB})$. Therefore, I will insist again on my question: how to simulate these $41 \mathrm{~KB}$ ? If they don't define exactly how to get to those $41 \mathrm{~KB}$, how are they going to make the comparisons between the different participants in the acquisition process? 


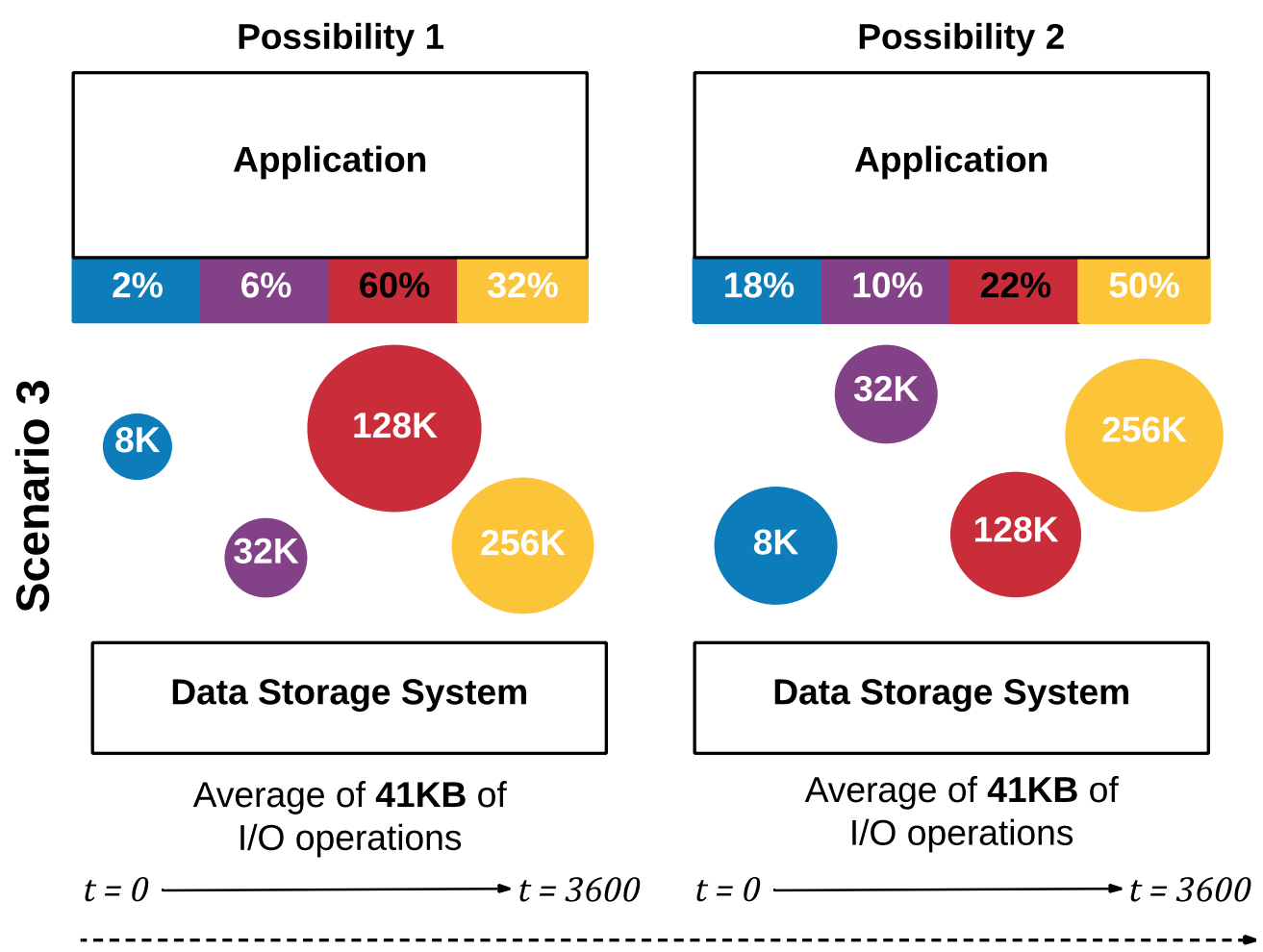

Time in seconds for the experiment $(t)$

Figure 3. Two possibilities to achieve an average of $41 \mathrm{~KB}$ of $\mathrm{I} / \mathrm{O}$ operations in a PoC performance experiment

Increasing the ontological description of Heidegger's understanding, Gadamer proposed his philosophical hermeneutics. He renamed the previous structures of understanding as "prejudices" and posed the central question for hermeneutics: How can we identify the legitimate prejudices from which we understand correctly? (Schmidt, 2012).

As we can see in Figure 3, both possibility 1 and possibility 2 produce "a truth" in relation to an average of $41 \mathrm{~KB}$ for the $\mathrm{I} / \mathrm{O}$ operations in this experiment. However, we question: (i) Are these the only possibilities in order to reach this average of $41 \mathrm{~KB}$ ? or (ii) How can we understand if the adopted distribution, despite being true for that moment, is also true for the original world where this system application resides? Therefore, we highlight Gadamer's thinking in relation to reciprocity, where "the doctor may have the medical knowledge, but unless he or she applies it appropriately it cannot become useful knowledge. Similarly, the teacher may have the subject expertise but, again, unless this is related to the educational needs of the learner it remains ineffectual. In both cases the appropriate application can only be achieved through dialogue."

In order to apply their specialist knowledge, professional practitioners such as actors in the context of $\mathrm{PoC}$, must understand to whom and within what context that knowledge is being applied. They must, in other words, become good listeners (Nixon, 2017, p. 72). In this specific scenario, we learned that any of the $\mathrm{N}$ possibilities existing in order to reproduce an average of $41 \mathrm{~KB}$ constitute a truth, that is, knowledge, but only "to a certain extent" and they are only specific according to some context or relationship (Nonaka \& Takeuchi, 1995, p. 73). However, here, the problem arises not in how to calculate an average, but whether this calculation can be considered as true in another world, that is, in the original world of an organization using the data storage solution. 


\section{Remember That IOPS are Not All Created the Same Way}

During our participation in the natural PoC habitat, we observed this as one of the most frequently encountered scenarios. Many actors in the context of the PoC seek to (re)use the results of one PoC in other PoCs. Although we understand this intention (reusability), we question a possible lack of understanding of the parts that "are connected" to the whole in the context of the PoC.

As we can see in the excerpt given in Table 5, a practitioner seeks to use the results of a $\mathrm{PoC}$ and, in some way, "normalize them," in order to be used in another PoC, such as: if a device is capable of performing 100,000 I/O operations in 1 millisecond, can I assume that this equipment is also capable of performing 1,000,000 of the same operations in a longer time, that is, 10 milliseconds? In other words, we note that the intention of this practitioner is to (re)use the production of knowledge that was based on one context (100,000 IOPS in 1ms) in another context (1,000,000 IOPS in 10ms).

Although this production of meaning is a truth "to a certain extent" according to Nonaka \& Takeuchi (1995), and specific to this context (that is, 100,000 IOPS in 1ms), the intention of this practitioner is to "transport" this knowledge and characterize it as an "absolute truth" for any context. It is noteworthy that we do not question the results per se produced during the PoC activity, but we ask whether this knowledge could be "transported" to another context, without the knowledge of its parts. Therefore, we highlight the issue of relevance in the production of knowledge in this exercise.

We understand to a certain extent that reusability is desirable, not as an absolute and unquestionable truth in any context, but as a contributed experience for practitioners in the context of PoC to "reflect on" a past and try to understand if past experiences can be "connected" in the current knowledge flow in the PoC activity. In other words, a simple change in the context of $\mathrm{PoC}$, for example, a different parameterization in the software tool for the I/O simulation or the average response time calculated for read and write operations, could provoke a change in the composition of the final results and increase the probability of the domino effect in the context of the PoC (Neto et al., 2018). Because those "results live

Table 5. Remember that IOPS are not all created the same way

[PoC practitioner] I have been thinking about something and would love some feedback. If a customer asks for a $100 \mathrm{~K}$ IOPS, however, they are OK with a $5 \mathrm{~ms}$ average latency. Does it mean I can assume 20 K IOPS at 1 ms latency? My limited logic is telling me that if in 1 ms (of time) I am doing X amount of jobs (IOPS) that should mean that in $2 x$ that time I will be able to do double the job, so 100 K IOPS at $1 \mathrm{~ms}$ means 1 M IOPS at $10 \mathrm{~ms}$ latency. Is there any formula to apply here? I have many use-cases where customers are more than OK with a 5 ms latency, so will that mean I can divide the IOPS requirement by 5 if I have IOPS numbers at $1 \mathrm{~ms}$ ? [Answer from a different PoC Practitioner] Nope. This reasoning is a bit too simplistic and does not match reality for a couple of reasons: Latency increases not linearly but tends to be more of a logarithmic curve with a hockey stick configuration. You may perfectly deliver $100 \mathrm{~K}$ IOPS at $1 \mathrm{~ms}$ and then after the breakpoint (could be 120 $K I O P S)$ go straight in the 5-10 ms or more. It's not because you can lift $40 \mathrm{~kg}$ in one second that you can lift 1,000 kg in 25 seconds. Also, other things come into play for latency, such as the size of the IO (block size), parallelism (how many IO can you do in parallel versus single threaded IO), and probably a few others. It's not linear, so you can't just divide. 
within a context", we cannot simply extract and transport them to a different world without the knowledge of its parts, which is, its past and its future (Neto et al., 2020a). On the other hand, based on the principle of suspicion that requires a "sensitivity to possible 'biases' and systematic 'distortions' in the narratives collected from the participants" (Klein \& Myers, 1999, p. 72), if we consider the results obtained in this PoC activity as a truth, we question whether these values were only obtained due to the use (or misuse) of the software tool for the generation and simulation of I/O. For example, a hypothesis would be an improper contribution in the use of the software tool for the generation and simulation of $\mathrm{I} / \mathrm{O}$, due to the lack of experience of the $\mathrm{PoC}$ practitioner or a misuse in the adoption of its parameters for the generation, read, and write operations in the data storage system. Therefore, comprehension occurs as a fusion of the so-called "past horizon" of the text (i.e., past record of the PoC activity) with the horizon holds an understanding of its parts and the context.

Thus, all understanding starts from our prejudices: the thrown-into-this-world character of understanding implies that all of our prejudices are inherited from our past (Schmidt, 2012). In other words, Gadamer "invariably relates to our understanding of the past, and of how we interpret the past with reference to the sources available to us" (Nixon, 2017, p. 49). Gadamer's central argument is that our horizons of understanding are never static. He insists on "the fundamental non-definitiveness of the horizon in which [our] understanding moves" (Nixon, 2017, p. 49). Therefore, in the context of PoC, if there is no past, there is no prejudice.

\section{The Dialectic of the Requirements Versus the Results in the Context of PoC}

During our observations and participation in the natural $\mathrm{PoC}$ habitat, we identified a phenomenon that we call the dialectic of the requirements and results in the context of PoC. As illustrated in the excerpt in Table 6, the specialist practitioners of the organization on the client side were required to perform all performance experiments on a data storage system with no more than $40 \%$ utilization of the data disks.

Based on Gadamer's philosophical hermeneutics, we question whether these practitioners determined this metric (i.e., less than $40 \%$ of disk usage) in relation to their horizon where, according to Gadamer (2013), a person with a horizon knows the relative meaning of everything, but only within that particular horizon. In addition, many others (such as other practitioners in the context of $\mathrm{PoC}$ ) may be "traveling the same path, but from different directions and with different destinations in mind." In other words, any attempt at mutual understanding involves constant mediation and readjustment of both fields of perception (our emphasis) (Nixon, 2017) and the "meanings are made at the point of intersection where our horizons overlap" which could be between the viewer and the viewed, or the listener and the orator, for example. "The object of interpretation does not simply surrender its meaning as a form of divine revelation" and "meaning is never self-evident, but is always a result of an interpretive act" thus the interpreter and the interpreted have a mutual meeting point; a type of consensus agreement (Nixon, 2017, p. 49). In the same way, we observe the occurrence of this dialectic in the context of PoC, where the authors of these requirements (such as, for example, a practitioner in the context of $\mathrm{PoC}$ on the side of an organization) believe in their production of meaning as an "absolute truth", whereby often this production of meaning is characterized as illusory when mediated and readjusted in different fields of perception of the PoC context (Figure 4). 
Table 6. The dialectic of the requirements and the results in the context of PoC

In the test plan sent to us, they want to perform all performance experiments, especially the random ones, with no more than $40 \%$ utilization of the disks in our equipment. Before I talked to you, I asked them about it, and they told me that it is an industry standard in performance testing. They have hired an external team specialized in benchmarks and are strictly following their recommendations. [Answer from a different PoC practitioner] Can you ask where they got it from? I understand that each manufacturer has its recommendations and best practices, but I do not agree with this generalization, especially if they are unaware of our architecture. So, the disk may be at $20 \%$ utilization with a $3 \mathrm{~ms}$ latency, is everything okay?

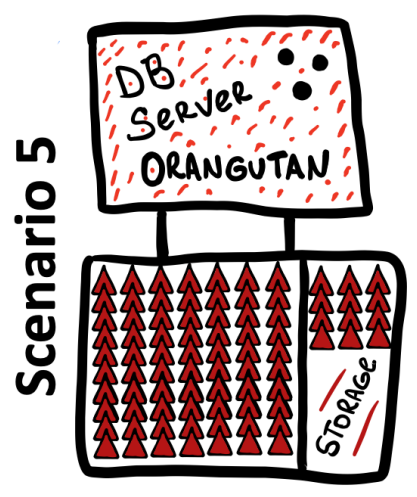

Practitioner A

\begin{tabular}{l} 
Requirements: \\
- Perform ance: $250 \mathrm{~K}$ IOPS \\
- Avg. ResPonse Time: $1 \mathrm{~ms}$ \\
-Avg. Block size: $45 \mathrm{~K}$ \\
\hline ResulTS: \\
- Performance: 260K IOPS \\
-Avg. ResPonse Time: $24 \mathrm{~ms}$ \\
-Avg. Block size: $45 \mathrm{~K}$
\end{tabular}

\section{Practitioner B}

\section{Requirements:} - Perform Ance: N250K IOPS - Avg. Response Time: $11 \mathrm{~ms}$ - Avg. Block size : $45 \mathrm{~K}$ ?

\section{RESULTS:}

Performance: $280 \mathrm{~K}$ IOPS

Avg. Response Time: $\sim 0.9 \mathrm{~ms}$ Avg. Block size: $16 \mathrm{~K}$

Figure 4. The dialectic of the requirements versus the results in the context of PoC

As can be seen in Figure 4, the practitioner on the organization side (Practitioner A) presented the following requirements and results of an experiment in the context of the PoC: (i) Requirements: a performance of approximately 250,000 IOPS, with an average response time of approximately 1 millisecond, using an average size of $45 \mathrm{~K}$ of data block for the $\mathrm{I} / \mathrm{O}$ operations; and (ii) Results: a performance of ap-proximately 260,000 IOPS, with an average response time of approximately 2.4 milliseconds, using an average size of $45 \mathrm{~K}$ of data block for the I/O operations. However, another practitioner in the context of PoC (Practitioner B) presented different results using an average size of $16 \mathrm{~K}$ of data block with a performance of approximately 880,000 IOPS, with an average response time of approximately 0.9 milliseconds.

Therefore, we highlight Gadamer's thinking in relation to hermeneutic reflection that can be critical when exposing the prejudices of an ideology, such as why practitioner A used a $45 \mathrm{~K}$ data block size, and practitioner B used a $16 \mathrm{~K}$ data block size for the same database? According to Gadamer, all interpretive understanding questioned and provoked reflection on the preconceptions in conflict, whereby "we seek to understand what is there-in fact, to understand better through the perception of someone else's prejudice" (i.e., prejudice relates to ideology or communicating distortions). "Hermeneutic reflection opens up possibilities for understanding that would not have occurred without it, but in itself it is not a criterion of truth." Further, there is a normal desire to perpetuate a conversation freely without fear of domination, for example, and hermeneutics is supposed to "expose the speakers" prejudices 
and to question them" (Schmidt, 2012, p. 159). In this scenario and under certain conditions, it is possible to have an illusion of conscience in which "the critique of 'false consciousness' becomes an integral part of hermeneutics" (Ricoeur, 2016, p. 153), where the change in emphasis of understanding of the other in order to understand the world of his own work implies a corresponding change in the conception of the "hermeneutic circle". In other words, knowledge production/dissemination can be characterized as a distorted communication. Ricoeur explained that the way to better understand an author (i.e., a PoC practitioner) is to unfold the revealing power implicit in his/her own discourse, even beyond the limited horizon of the practitioner's own existential situation, where it is possible to "refute fallacious views about the concept of interpretation. Primarily, appropriation does not imply any direct congeniality of one soul with another. Nothing is less inter-subjective or dialogical than the encounter with a text; what Gadamer calls the fusion of horizons expresses the convergence of the world horizons of the writer and the reader. The ideality of the text remains the mediator in this process of the fusion of horizons" (Ricoeur, 2016, p. 154).

\section{The "Famous" Comparisons in the Context of PoC}

We observed numerous PoCs where their practitioners sought to establish different comparisons of their current activity with other activities, whether they were previously performed by these practitioners or different $\mathrm{PoC}$ activities performed by other practitioners. Thus, we understand that the main purpose of these comparisons is to allow these practitioners to (re)use an experience, a situation, or a knowledge produced in a PoC for their current horizon. However, we highlight an excerpt from the scenario presented in Table 7, where a database administrator from one organization intends to compare a clone operation (i.e., a copy) of a database of 1 Gigabyte (GB) versus a clone of a 1TB database (that is, 1000 GB).

We highlight the basic elements of hermeneutical thinking, where although Gadamer had not solved the question of how we can determine which prejudices are legitimate or not within the merging of horizons, but rather only tells us that "legitimate prejudices are based on the things in itself, that correct understanding occurs when the parts and the whole form a unit of meaning, that distance, temporal or not, will help this process, and that understanding occurs as the fusion of horizons" (our emphasis) (Schmidt, 2012, p. 124). Thus, the production of meaning (grounded by the hermeneutics circles) is guided by a possible consensus between the potential customer and the individual who seeks to develop and execute the activity for example, a PoC practitioner. Hence, according to Gadamer (1976), understanding will only occur "through estrangement, for only failure to attempt to understand what is said within a system of intersubjectivity can lead one to penetrate the opinion of the other in the pursuit of its rationality and truth" (Neto et al., 2020a, p. 130).

Table 7. The famous comparisons in the context of PoC

But we are not comparing the same thing, are we? I know that the DBA (database administrator) wants to see the time of the database clone, but he is comparing a clone of a database with a table that must have a maximum of $1 \mathrm{~GB}$ (with no load-no I/O operations happening) versus a clone of a database of $1 \mathrm{~TB}$ (with I/O operations). How will they compare? No matter how long it took, do you really believe they have databases that are 1 GB in size and have no I/O operations? 
For Gadamer (1976), according to Schmidt (2012, p. 109), understanding is a projection with a thrown-into-this-world character, and this "thrown character means that we always un-derstand in some way and, therefore, that any act of understanding begins with the previous structures of understanding and interprets the latter as something. Therefore, the interpreter cannot escape the hermeneutic circle and obtain direct knowledge."

\section{CONCLUSION}

This research aims to contribute to the body of literature in the field of PoC knowledge, introducing a new perspective on knowledge flow in the context of PoC, in a way which is not how we imagined it before we started the research. In other words, before the elaboration of this research, we envisaged that the production and dissemination of knowledge would only occur at the end of the PoC activity. Indeed, we ourselves have been transformed by an aspect of the contribution of hermeneutics in the context of $\mathrm{PoC}$, the approach using the theoretical lens of philosophical hermeneutics as proposed by Gadamer. Philosophical hermeneutics promotes the fact that conversations (dialogues) within a $\mathrm{PoC}$ are the messages (the initial flows) that contribute to the formation of the subjects' discourse, thus providing the activity with a socio-technical context and contributing to the formation of the learning process as a critical formation based on the practitioners' hermeneutic circles.

After a long immersion period (30 months) in the natural $\mathrm{PoC}$ habitat, participating directly and indirectly in 80 complex PoC activities and interacting with 97 practitioners, we learned that the "true knowledge" in the PoC activity does not in reality arise at the end of the activity, but rather is born and then constantly transformed through constant learning cycles during the formation of the flow of knowledge grounded by a practice context model and the various hermeneutical circles. For future work, we intend to analyze this practice context model using the theoretical lenses of Networking Theory. Thus, in the context of PoC, understanding from the perspective of hermeneutics appears as something produced in existing conversations (dialogues), instead of being only reproduced by interpreters when they find a text, action, or result in the journey towards understanding something. In other words, in the context of PoC, every understanding is interpretive because of hermeneutic circles and, according to Gadamer, every interpretive understanding requires application. Thus, application is an essential part of the hermeneutic process, as well as the flow of knowledge, such as interpretation and understanding, which are also contained in the entire process of knowledge production and dissemination in the context of PoC.

Therefore, the job of the interpreter (that is, whoever analyzes the results of a $\mathrm{PoC}$ ) is not simply to reproduce the messages of the interlocutor he/she interprets, or the results collected from previous PoC activities, but rather to also express his/her opinion of how and when he/she deems it appropriate to do so (i.e., reproduce and interpret) based on the context. In other words, if we want to properly understand the knowledge flow in a PoC activity, we will have to follow their every moment and action, in each concrete situation in a new, different, and collaborative way with other practitioners and their communities of practice, and definitely not in isolation.

In this paper, we have presented a novel perspective on the formation of knowledge flow in the context of PoC, that in some way present the $\mathrm{PoC}$ practitioner as the interpreter of the reality that is exposed to him/her. This reality in PoC is full of artifacts, data, theories, experiences and unknowns that are confronted by other actors - theories, and experiences which are part of a certain worldview which is the practitioner's horizon. On the one hand, a particular PoC practitioner could say that another practitioner has a pre-understanding of the 
reality but is only "unveiling" the context that is established between PoC practitioners which permits further interpretation and understanding. In hermeneutics, as in Context Engineering (Roque, 2004, p. 121), "it is intended to involve the production of discourse on the relationship of the parts with the whole, or of mediators with their context, of elements that allow the production of meaning". According to Gadamer, any part of a text (or in the context of our research, any flow of knowledge in the context of $\mathrm{PoC}$ ) is indeterminate in relation to its meaning, where "only from the context of the whole can the meaning of the parts be understood, and vice versa" (Schmidt, 2012, p. 26).

Thus, we highlight the "connection" between the Practice Context Models (Neto et al., 2020b) and Hermeneutics (Neto et al., 2020a) aiming to provide a language and a "new way of thinking" for its practitioners in the development and execution of PoC. In other words, a "connection" with the aim to contribute to a better understanding of where these practitioners are (in the current context) or will be acting in the future (the new context), with respect to the development and the flow of knowledge in the context of PoC.

We conclude that knowledge flow occurs from different circles based on the hermeneutic circle, and the truth is nothing more than the composition of these circles, that is, something consensual, and agreed upon inter-subjectively between the participants of this circle. We highlight this definition while referring to the interpretation and the different circles in the PoC context, as we perceive an inseparable relationship of the interactions and dialogues of its practitioners in the search for knowledge of the performance of the technological artifacts under study during the development and execution of the PoC. Finally, it is the "knowledge of the context" (based on hermeneutic circles) or the history of these interactions that allows us to rationalize the production and dissemination of knowledge in the context of PoC.

\section{REFERENCES}

Almeida, A. (2006). Arquitetura de redes de armazenamento de dados [Architecture of data storage networks]. Universidade de Campinas, Brazil. http://repositorio.unicamp.br/jspui/handle/REPOSIP/276100

Angrosino, M. (2007). Qualitative research kit: Doing ethnographic and observational research. Sage.

Athilingam, P., Jenkins, B.A., Zumpano, H., \& Labrador, M.A. (2018). Mobile technology to improve heart failure outcomes: A proof of concept paper. Applied Nursing Research, 39(October 2017), 26-33. https://doi.org/10.1016/j.apnr.2017.10.018

Barnes, J.D., Katzer, R.D., Potluri, D., \& Stone, M.J. (2009). Demonstrating proof of concept of a project with requirements component providing weights on importance and tracking with use cases (U.S. Patent No. US7509626B1). U.S. Patent and Trademark Office. https://patents.google.com/patent/US7509626B1/en

Batista, M. (2012). Hermenêutica filosófica e o debate Gadamer-Habermas [Philosophical hermeneutics and the Gadamer-Habermas debate]. Critica e Sociedade: Revista de Cultura Política, 2(1), 101-118. http://www.seer.ufu.br/index.php/criticasociedade/article/view/15000/9769

Chaim, R.M., Oliveira, E.C., \& Araujo, A.P.F. (2017). Proof of concept think! EHR platform. In 2017 12th Iberian Conference on Information Systems and Technologies (CISTI) (pp. 1-7). https://doi.org/10.23919/CISTI.2017.7975850 
Corbett, J.M. (2000). On being an elephant in the age of oblivion: Computer-based information systems and organisational memory. Information Technology \& People, 13(4), 282-297. https://doi.org/10.1108/09593840010359482

Coutinho, C.P. (2015). Metodologia de investigação em ciências sociais e humanas: Teoria e prática [Research methodology in social and human sciences: Theory and practice] ( $2^{\text {nd }}$ ed.). Edições Almedina.

De Bruyne, P., Herman, J., \& Schouteete, M. (1991). Dinâmica da pesquisa em ciências sociais [Dynamics of social science research] $\left(5^{\text {th }} \mathrm{ed}\right)$. Francisco Alves Editora.

Deetz, S. (1973). An understanding of science and a hermeneutic science of understanding. Journal of Communication, 23(2), 139-159. https://doi.org/10.1111/j.14602466.1973.tb00939.x

Elliott, S.N., Kratochwill, T.R., Littlefield Cook, J. \& Travers, J. (2000). Educational psychology: Effective teaching, effective learning ( $3^{\text {rd }}$ ed.). McGraw-Hill.

Engeström, Y. (2001). Expansive learning at work: Toward an activity theoretical reconceptualization. Journal of Education and Work, 14(1), 133-156. https://doi.org/10.1080/13639080123238

Gadamer, H.G. (1976). Philosophical hermeneutics. University of California Press.

Gadamer, H.G. (1999). Verdade e método: Traços fundamentais de uma hermeneutica filosófica [Truth and method: Fundamental features of a philosophical hermeneutics]. Editora Vozes.

Gadamer, H.G. (2008). Philosophical hermeneutics. University of California Press.

Gadamer, H.G. (2013). Truth and method. Bloomsbury Academic.

Gil, A.C. (1989). Métodos e técnicas de pesquisa social [Methods and techniques of social research] $\left(2^{\text {nd }}\right.$ ed.). Editora Atlas.

Glaser, B.G., \& Strauss, A.L. (1999). Discovery of grounded theory. Routledge.

Hasan, H. (2003). Information systems development as a research method. Australasian Journal of Information Systems, 11(1), 4-13. https://doi.org/10.3127/ajis.v11i1.142

Heidegger, M. (2005). Ser e Tempo [Being and time]. Editora Vozes.

Hirata, S., \& Bernal, V.B. (2009). Create a comparative analysis of an oracle database using $N A S$ and SAN storage architectures (EMC Proven Professional Knowledge Sharing). EMC Corporation. https://citeseerx.ist.psu.edu/viewdoc/download?doi=10.1.1.462.9105\&rep=rep1\&type= pdf

Kendig, C.E. (2016). What is proof of concept research and how does it generate epistemic and ethical categories for future scientific practice? Science and Engineering Ethics, 22(3), 735-753. https://doi.org/10.1007/s11948-015-9654-0

Klein, H.K., \& Myers, M.D. (1999). A set of principles for conducting and evaluating interpretive field studies in information systems. MIS Quarterly, 23(1), 67. https://doi.org/10.2307/249410

Lazar, J., Feng, J.H., \& Hochheiser, H. (2017). Research methods in human-computer interaction ( $2^{\text {nd }}$ ed.). Elsevier.

McAdam, R., McAdam, M., \& Brown, V. (2009). Proof of concept processes in UK university technology transfer: An absorptive capacity perspective. $R \& D$ Management, 39(2), 192-210. https://doi.org/10.1111/j.1467-9310.2008.00549.x

National Science Foundation. (2014). Partnerships for innovation: Accelerating innovation research-technology translation (NSF 14-569). https://www.nsf.gov/pubs/2014/nsf14569/nsf14569.htm 
Neto, A.J.R. (2004). Um estudo do desempenho dos protocolos iSCSI e fibre channel [A study of the performance of the iSCSI and fiber channel protocols]. Universidade de Campinas, Brazil. http://repositorio.unicamp.br/jspui/handle/REPOSIP/276309

Neto, A.J.R., Borges, M.M., \& Roque, L. (2020a). A "new" view of proof-of-concept practices through the lenses of activity theory and hermeneutics. Journal of Information Technology Research (JITR), 13(4), 118-135. https://doi.org/10.4018/JITR.2020100108

Neto, A.J.R., Borges, M.M., \& Roque, L. (2020b). Developing a proof-of-concept practices context model. In Proceedings of the 28th European Conference on Information Systems (ECIS), An Online AIS Conference, June 15-17, 2020. https://aisel.aisnet.org/ecis2020_rp/174

Neto, A.J.R., Borges, M.M., \& Roque, L. (2018). A preliminary study of proof of concept practices and their connection with information systems and information science. In Proceedings of the Sixth International Conference on Technological Ecosystems for Enhancing Multiculturality-TEEM'18 (pp. 270-275). https://doi.org/10.1145/3284179.3284226

Neto, A.J.R., Borges, M.M., \& Roque, L. (2019). Characterizing proof-of-concept practices using the lens of context engineering. In A. Siarheyeva, C. Barry, M. Lang, H. Linger, \& C. Schneider (Eds.), Information systems development: Information systems beyond 2020 (ISD2019 Proceedings). Springer. https://aisel.aisnet.org/isd2014/proceedings2019/ISDMethodologies/4/

Neto, A.J.R., \& Da Fonseca, N.L.S. (2007). Um estudo comparativo do desempenho dos protocolos iSCSI e Fibre Channel [A study of the performance of the iSCSI and fiber channel protocols]. IEEE Latin America Transactions, 5(3), 151-157. https://doi.org/10.1109/TLA.2007.4378498

Nixon, J. (2017). Hans-Georg Gadamer: The hermeneutical imagination. Springer. https://doi.org/10.1007/978-3-319-52117-6

Nonaka, I., \& Takeuchi, H. (1995). The knowledge-creating company: How Japanese companies create the dynamics of innovation. Oxford University Press.

Portocarrero, M.L. (2010). Conceitos fundamentais da hermenêutica filosófica [Fundamental concepts of philosophical hermeneutics]. Universidade de Coimbra, Portugal. http://www.uc.pt/fluc/lif/publicacoes/textos_disponiveis_online/pdf/conceitos_herm

Ricoeur, P. (2016). Hermeneutics and the human sciences: Essays on language, action and interpretation. Cambridge University Press.

Roque, L. (2004). Contribuição para uma engenharia do contexto [Contribution to context engineering]. Universidade de Coimbra, Portugal.

Saracevic, T. (1996). Ciência da informação: Origem, evolução e relações [Information science: origin, evolution and relationships]. Perspectiva em Ciência da Informação, 1(1), 41-62. http://portaldeperiodicos.eci.ufmg.br/index.php/pci/article/view/235

Schmidt, B. (2006). Proof of principle studies. Epilepsy Research, 68, 49-52.

Schmidt, L.K. (2012). Hermenêutica [Hermeneutics]. Editora Vozes.

Schön, D.A. (1983). The reflective practitioner: How professionals think in action. Basic Books.

Sergey, A.B., Alexandr, D.B., \& Sergey, A.T. (2015). Proof of concept center-A promising tool for innovative development at entrepreneurial universities. Procedia - Social and Behavioral Sciences, 166, 240-245. https://doi.org/10.1016/j.sbspro.2014.12.518 
Silva, K.J. da. (2012). Desempenho do protocolo NFSv4 em arquiteturas NAS sob efeito de alterações de parâmetros e da evolução da rede IP [Performance of the NFSv4 protocol on NAS architectures under the effect of parameter changes and the evolution of the IP network]. Universidade de São Paulo, Brazil. https://www.ipt.br/pos_graduacao_ipt/solucoes/dissertacoes/214desempenho_do_protocolo_nfsv4_em_arquiteturas_nas_sob_efeito_de_alteracoes_de parametros_e_da_evolucao_da_rede_ip.htm

Simitci, H., Malakapalli, C., \& Gunturu, V. (2001). Evaluation of SCSI over TCP/IP and SCSI over fibre channel connections. HOT 9 Interconnects. In Symposium on the High Performance Interconnects, January (pp. 87-91). https://doi.org/10.1109/HIS.2001.946698

Stagliano, N. (2016). Hermenêutica-Conceitos e características [Hermeneutics-Concepts and features].

https://simoesstagliano.jusbrasil.com.br/artigos/335787147/hermeneutica-conceitos-ecaracteristicas

Taleb, N.N. (2010). The black swan: The impact of the highly improbable. Random House, Inc.

Trieschnigg, R.B. (2010). Proof of concept: Concept-based biomedical information retrieval. University of Twente. https://doi.org/10.3990/1.9789036530644

Zimmermann, J. (2015). Hermeneutics: A very short introduction. Oxford University Press. 